\title{
Eco Friendly Management of Mycoflora Associated with Trichosanthes Anguina L. and Trichosanthes Dioica Roxb
}

\author{
Abu-Al-Islam¹And Shamim Shamsi* \\ Department of Botany, University of Dhaka, Bangladesh \\ prof.shamsi@gmail.com
}

\begin{abstract}
An investigation was carried out to control the fungi associated with two common vegetables of Bangladesh viz. Trichosanthes anguina L. and T. dioica Roxb. during the tenure of June to December, 2014. Apparently fresh vegetables were collected from five local markets of Dhaka city near the campus of Dhaka University. After harvesting the vegetables are contaminated with fungi within 3-4 days of short storage. Fungi associated with the samples were isolated from the samples following "Tissue Planting" method on PDA (Potato Dextrose Agar) medium. Seven species of fungi namely Aspergillus flavus, A. fumigatus, A. niger, Fusarium sp., Penicillium sp., Rhizopus stolonifer and Trichoderma viride were to be associated with the above mentioned vegetables. Aspergillus niger was the predominating fungi associated with snake gourd and pointed gourd. To control the fungi three plant extracts namely Allium cepa, A. sativum and Zingiber officinale and two chemicals namely sodium bicarbonate and sodium chloride were selected for evaluating their effect on the radial growth of seven species of fungi isolated from fresh vegetagles. Extract of Allium sativum and both the chemical were showed $100 \%$ radial growth inhibition of the isolated fungi at $20 \%$ concentrations.
\end{abstract}

Keywords: Management, Mycoflora, fresh vegetables, Trichosanthes anguina, T. dioica

\section{INTRODUCTION}

Vegetables are parts of plant that consumed by humans as food and as well as part of savory course or meal. Vegetables are a common and broadly accepted food in our country. The commonly available vegetables are pointed gourd, snake gourd, bitter gourd, potato, bean etc. Among all the vegetables Trichosanthes anguina L. (Snake gourd) and Trichosanthes dioica Roxb. (Pointed gourd) are very popular.

The importance of these vegetables in human nutrition is best known. Pointed gourd and snake gourd can be eaten as cooked and play an important role in human nutrition, being mostly low in fat and carbohydrates, but high in vitamins, minerals and fiber. Vegetables are rich and comparatively cheaper source of vitamin and minerals. Their consumption in sufficient quantities provides taste, palatability and increase appetite. Vegetables are currently reckoned as important adjunct for maintenance of good health and beneficial in protecting

against some degenerative diseases. They also play a key role in neutralizing the acids that are formed during digestion. Many people in rural and urban areas fully depend on vegetable cultivation and selling it in the markets. But it is the matter of deep concern that a remarkable portion of harvested vegetables are being lost due to mismanagement of the vegetables during transit and storage, as a result fungal infection occurs and subsequently vegetables are spoiled. For preventing loss of the vegetable it needs proper management of disease.

Many research have been done on nutritional values of the vegetables but little information is available regarding association of fungi with fresh vegetable and its control (Bose 1993 and Haque and Shamsi. 2011).

Present research has been undertaken to find the association of fungi with vegetables and their management.

\section{Materials AND Methods}

The present study is based on two selected vegetables namely Trichosanthes anguina and Trichosanthes dioica. The samples of these vegetables were collected from five different markets namely Ananda bazar, Hatirpul bazar, Karwan bazar, Palashi bazar and Segunbagicha bazaar of 
Dhaka city. Each market was visited for the trice to collect samples. For each experiment One $\mathrm{kg}$ fresh vegetables were collected. Samples were collected during the period of June to December 2014.

Morphological studies: Detail morphological studies of the fungal isolates were made in order to determine their identity. For microscopic observations fungal structure like mycelia, spore bearing structure and spores were scrapped off from the surface with a scalpel or blade or picked up with a needle and was mounted in lacto phenol over a clean slide. In case of hyaline structure, a little amount of aniline blue (cotton blue) was added to the mounted fluid. All specimens, included in the present study were preserved in Mycology and Plant Pathology section, Department of Botany, University of Dhaka, Bangladesh.

The fungi were isolated from samples following the "Tissue Planting Method". This method mostly induced heavy sporulation under ordinary room temperature.

Water extract of three angiospermic plant and two chemicals were used to evaluate their antifungal properties against the fungi associated with $T$. anguina and $T$. dioica in vitro.

Preparation of plant extract and chemical solutions and application: A total of three plant extracts namely Allium cepa, A. sativum and Zingiber officinale were selected for evaluating their effect on the radial growth of seven species of fungi isolated from fresh vegetables.

The desired parts of each plant were thoroughly washed in tap water, air dried and were prepared by crushing known weight of fresh materials with autoclaved water in ratio of $(1: 1, w / v)$. The mass of a plant part was squeezed through fine cloth and the extracts were centrifuged at $3000 \mathrm{rpm}$ for $20 \mathrm{~min}$. The supernatants were filtered through Whatman filter paper No.1 and the filtrate was collected in $250 \mathrm{ml}$ Erlenmeyer conical flasks. The requisite amount of the filtrate of each plant extract was mixed with PDA medium in which plant extracts were in 5, 10 and $20 \%$ concentrations.

A total of two chemicals namely sodium bicarbonate and sodium chloride were selected for evaluating their effect on the radial growth of seven species of fungi isolated from fresh vegetables. Both the chemicals were dissolved separately in autoclaved water in ratio of $(1: 1, \mathrm{w} / \mathrm{v})$. The requisite amount of the solution was mixed with PDA medium in which chemicals were in 5, 10 and 20\% concentrations.

Inoculation of the test pathogens: The medium thus prepared was poured into sterilized Petri plates and was allowed to solidify. Each Petri plate was inoculated centrally with a $5 \mathrm{~mm}$ agar disc cut from the margin of actively growing culture of the test pathogens. In the control set, a Petri plate containing PDA medium with the requisite amount of distilled water instead of a plant extract was also inoculated with agar disc of the test pathogen in the same as described above. Three replications were maintained for both experiments and control sets. The inoculated Petri plates were incubated at $25 \pm$ $2^{\circ} \mathrm{C}$. The radial growth of the colonies was measured after 7 days of incubation.

\section{RESUlTS AND DisCUSSIONS}

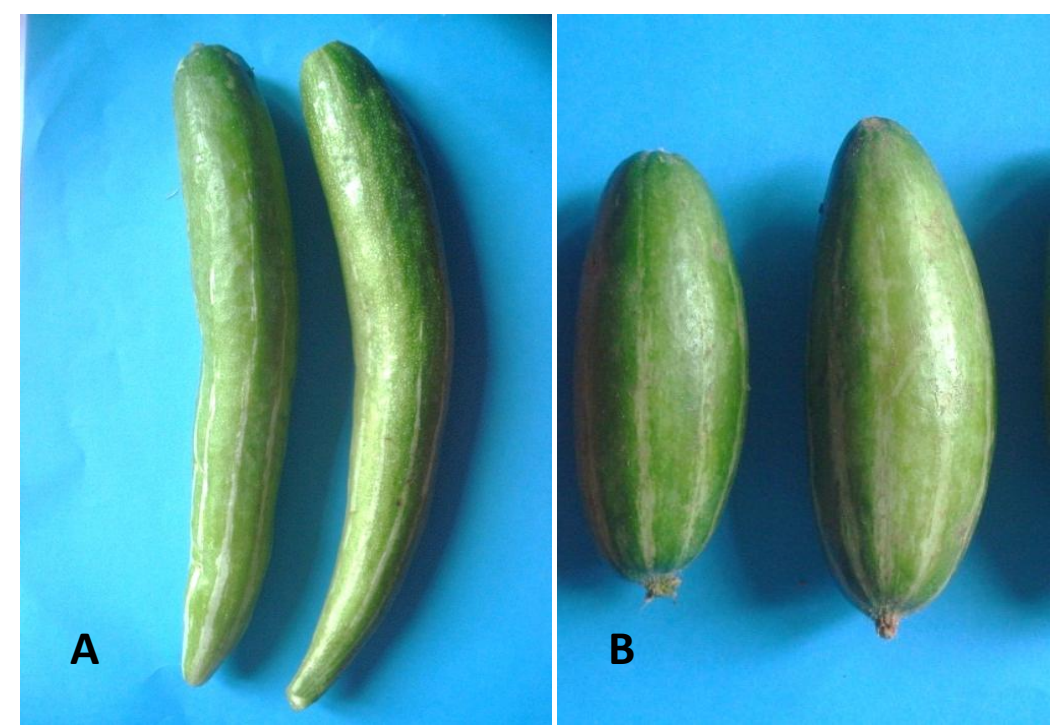

Fig1. Trichosanthes anguina (A) and T. dioica (B) Fresh vegetables 
In the present study, a total of 30 fresh samples of $T$. anguina and $T$. dioica were examined (Fig. 1 A-B). Five genera of Deuteromycetes namely Aspergillus, Fusarium, Penicillium Rhizopus and Trichoderma were found to iso; ated from fresh vegetables. The genera were characterized and key was provided to separate them. The species determinations of these genera were made wherever possible with available literatures (Bernate and Hunter 1972, Booth 1972, Thom and Rapper 1945, Kenneth and Rapper 1949).

Table 1 showed that five fungal species were isolated from $T$. anguina. The isolated fungi were $A$. niger, A. flavus, A. fumigatus, Fusarium sp. and R. stolonifer. Frequency percentage of association of Aspergillus niger was highest (78.6) in the sample collected from Karwan bazar followed by (53) in the sample of Ananda bazaar, (41.1) in the sample of Palashi bazar and (41.0) in the sample of Hatirpul bazaar. Lowest frequency percentage of the fungus association was recorded (37.8) in the sample of Segunbagicha bazar. Nest to A. niger, A, fumigatus was the predominating fungus of the $T$. anguinus which was isolated from all the market studied. Frequency percentage of association of the fungus was highest (29.6) in the sample of Ananda bazar and it was lowest (11.6) in the sample of Karwan bazar. Next position was occupied by A. flavus. Frequency percentage of association of the fungus was highest (16.1) in the sample collected from Palashi bazar and it was lowest (3.5) in the sample of Ananda bazar. Frequency percentage of association of S. stolonifer was highest (8.5) in the sample of Palashi bazaar and it was lowest (4.0) in the sample of Segunbagicha bazaar. Fusarium sp. was exclusively isolated froe the samples of Segunbagicha bazaar. Frequency percentage of association of the fungus was 8.9.

Table1. Frequency percentage of association of fungi with fresh Trichosanthes anguina collected from five vegetable markets of Dhaka city

\begin{tabular}{|c|c|c|c|c|c|c|c|}
\hline \multirow{2}{*}{ Name of isolates } & \multicolumn{5}{|c|}{$\begin{array}{c}\text { Frequency (\%) fungi isolated } \\
\text { from different markets }\end{array}$} & \multirow{2}{*}{ Total } & \multirow{2}{*}{ Mean } \\
\cline { 2 - 7 } & $\mathrm{A}$ & $\mathrm{H}$ & $\mathrm{K}$ & $\mathrm{P}$ & $\mathrm{S}$ & & \\
\hline Aspergillus flavus & 5.3 & 07 & 10 & 16.1 & 11.1 & 49.5 & 9.9 \\
\hline A. fumigatus & 29.6 & 21.3 & 11.6 & 13.5 & 18.6 & 92.5 & 18.9 \\
\hline A. niger & 53.0 & 41 & 78.6 & 41.1 & 37.8 & 224.4 & 44.9 \\
\hline Fusarium sp. & 0 & 0 & 0 & 0 & 8.9 & 8.85 & $\mathbf{1 . 7}$ \\
\hline Rhizopus stolonifer & 0 & 6 & 0 & 8.5 & 4.0 & 18.5 & 8.5 \\
\hline
\end{tabular}

$A=$ Ananda bazaar, $H=$ Hatirpul bazaar, $K=$ Karwan bazaar, $P=$ Palashi bazaar and $S=$ Segunbagicha bazaar

Table2. Frequency percentage of association of fungi with fresh Trichosanthes dioica collected from five vegetable markets of Dhaka city

\begin{tabular}{|l|l|l|l|l|l|l|l|}
\hline \multirow{2}{*}{ Name of isolates } & \multicolumn{9}{|l|}{$\begin{array}{l}\text { Frequency (\%) fungi isolated } \\
\text { from different markets }\end{array}$} & \multirow{2}{*}{ Motal } \\
\cline { 2 - 6 } & A & H & K & P & S & & \\
\hline Aspergillus favus & 13.5 & 09 & 9.3 & 0 & 8.0 & 39.3 & 7.86 \\
\hline A. fumigatus & 7.3 & 13 & 4.6 & 2.7 & 61.5 & 89.1 & 17.8 \\
\hline A. niger & 63.3 & 33 & 83.6 & 58.5 & 19.5 & 257.9 & 51.58 \\
\hline Fusariumsp. & 0 & 0 & 0 & 0 & 2.2 & 2.2 & 0.44 \\
\hline Penicillium sp. & 2.3 & 0 & 0 & 0 & 0 & 2.3 & 0.46 \\
\hline Rhizopus stolonifer & 0 & 25.3 & 6 & 5.6 & 0 & 36.9 & 7.38 \\
\hline Trichodermaviride & 6.6 & 2.3 & 0 & 0 & 1.6 & 10.5 & 2.1 \\
\hline
\end{tabular}

$A=$ Ananda bazaar, $H=$ Hatirpul bazaar, $K=$ Karwan bazaar, $P=$ Palashi bazaar and $S=$ Segunbagicha Bazaar.

Table2. Showed that seven species of fungi namely Aspergillus flavus, A. fumigatus, A. niger, Fusarium sp., Penicillium sp., Rhizopus stolonifer and Trichoderma viride were isolated from T. dioica.. Frequency percentage of association of Aspergillus niger was highest (81.6) in the samples collected from Karwan bazaar followed by (63.3) in the samples of Ananda bazaar, (58.5) in the sample of Palashi bazaar and (33.0) in the samples of Hatirpul bazaar. Lowest frequency percentage of the fungus association was recorded (19.5) in the samples of Segunbagicha bazaar. Nest to $A$. niger, A, fumigatus was the predominating fungus of the T. anguinus which was isolated from all the market studied. Frequency percentage of association of the fungus was highest (61.5) in the samples 
of Segunbagicha bazaar and it was lowest (2.7) in the samples of Palashi bazar. Next position was occupied by A. flavus. Frequency percentage of association of the fungus was highest (13.5) in the samplse collected from Ananda bazaar and it was lowest (8.0) in the sample of Segunbagicha bazar. Frequency percentage of association of S. stolonifer was highest (8.5) in the samples of Palashi bazaar and it was lowest (4.0) in the samples of Segunbagicha baazar. Fusarium sp. was exclusively isolated from the samples of Segunbagicha bazaar. Frequency percentage of association of the fungus was 2.2. Penicillium sp. was exclusively isolated from the samples of Ananda bazaar. Frequency percentage of association of the fungus was 2.2. Frequency percentage of association of Trichoderma viride fungus was highest (6.6) in the samples of Ananda bazaar and it was lowest (1.6) in the samples of Ananda bazaar.

Three plants extract namely Allium cepa, Allium sativum and Zingiber officinale were applied for in vitro management of isolated fungi.

Plant extract of A. cepa, A. sativum and Z. officinales completely inhibited the radial growth of all the isolated fungi at $20 \%$ concentration. ( Figs. 2-4).

All the plant extract of onion, garlic and zinger were showed $100 \%$ control at $20 \%$ concentration.

Two chemicals namely sodium bicarbonate and sodium chloride were applied for in vitro management of isolated fungi.

Sodium bicarbonate and sodium chloride completely inhibited the radial growth of all the isolated fungi at $20 \%$ concentration (Figs. 5-6).

Present findings indicates that $A$. niger is the predominating fungi with both vegetables in Karwan bazaar . Shamsi et al. (2014) highest frequency percentage of association of the fungus in the same market as air borne fungi.

Fig. 2, 3, 4, 5 and 6 shows the effect of Allium cepa, A. sativum, Zingiber officinale, Sodium bicarbonate and Sodium chloride on seven fungi isolated from fresh vegetables.

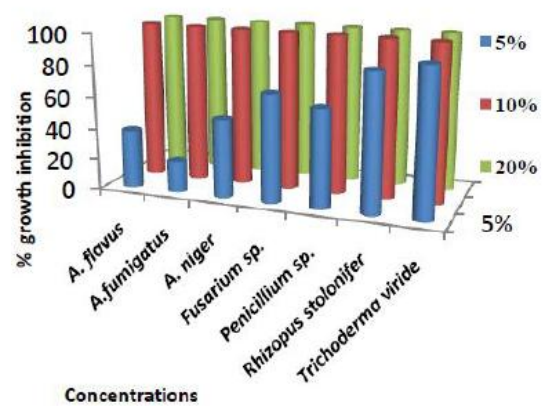

Fig2. Allium cepa

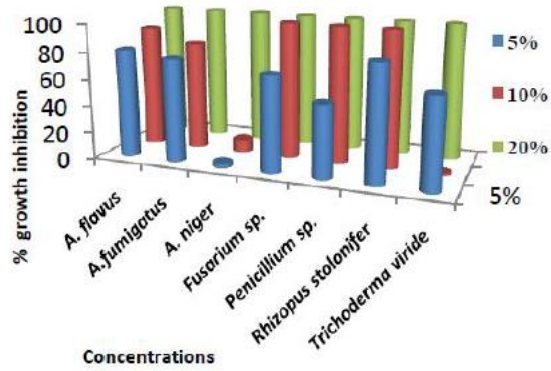

Fig4. Zingiber officinale

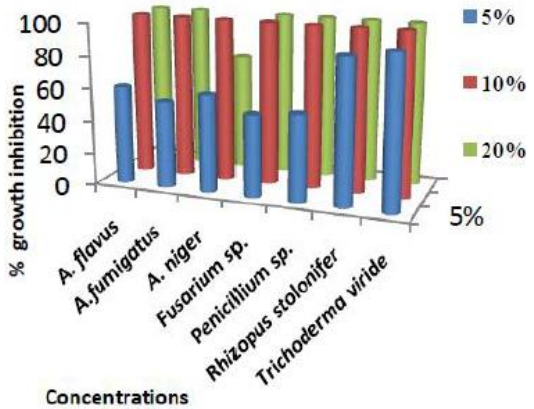

Fig3. A.sativum

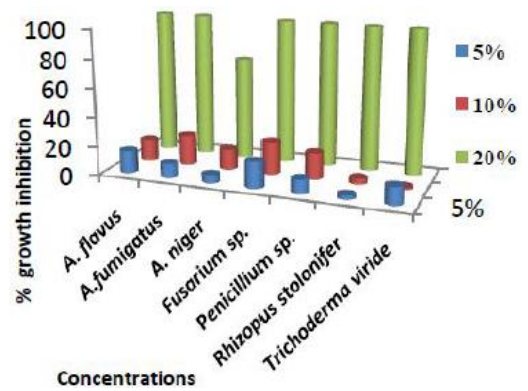

Fig5. Sodium bicarbona

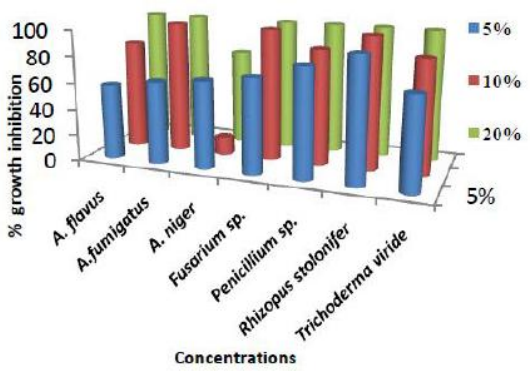

Fig6. Sodium chloride 


\section{ACKNOWLEDGEMENTS}

The first author (AK) gratefully acknowledges to "Ministry of Science and Technology", People's Republic of Bangladesh for providing their financial support in her research through NST fellowship.

\section{REFERENCES}

[1] Barnett, H. L. and B. B. Hunter. 2000. Illustrated Genera of Imperfect Fungi. (4th edn.), Burgessbub. Co. Minneapolis. pp. 218.

[2] Booth C 1971. The Genus Fusarium. CommonwealthMycologicalInstitute.Kew, Surrey, England. pp. 237.

[3] Bose, T. K. 1993. Vegetables crops, Department of Horticulture, Bidhan Chandra Krishi Viswavidyalaya, Kalyani 741235. West Bengal. India. pp . 615

[4] Ellis, M. B. 1971. Dematiaceous Hyphomycetes. The Commonwealth Mycological Institute, England, pp. 608.

[5] Ellis, M. B. 1976. More Dematiaceous Hyphomycetes. The Commonwealth Mycological Institute, England, pp. 507.

[6] Ellis, M.B. and Ellis J.P. 1997.Micro Fungi on Land Plants. An identification Handbook.

[7] The Commonwealth Mycological Institute, England. Pp .868.

[8] Haque, J. and S. Shamsi. 2011. Study of fungi associated with some selected vegetable of Dhaka city, Bangladesh J. Sci. Res. 24 (2): 181-18

[9] Rapper, M. F. and Thom, C. 1949.A Manual of the Penicillium. The Willium \& Wilkins Company, Baltimore, MD., U. S. A. pp. 27.

[10] Raper, K.B and D. I.Fennel. 1965. The Genus Aspergillus. Willium\&wilkins, Baltimore, MD. Pp. 57.

[11] Shamsi, S., N. Naher, M. T. I. Chowdhury and A.K.M. Wahiduzzaman. 2014. Seasonal variation in vegetable market of Karwan Bazar, Dhaka, Bangladesh. Journal of Bangladesh Academy of Sciences. 38(1):49-59.

[12] Spurr, H.W.J and R.E. Wetly 1972. Incidence of tobacco leaf microflora in relation to brown spot disease and fungicidal treatment. Phytopathol.62: 916- 920. 